\title{
Warfarin Quality Metrics for Hospitalized Older Adults
}

\author{
Jessica Cohen ${ }^{1,2}$ Liron Sinvani ${ }^{1,2}$ Jason J. Wang ${ }^{2,3}$ \\ Renee Pekmezaris ${ }^{2,3}$ Alex C. Spyropoulos 2,4 \\ ${ }^{1}$ Division of Hospital Medicine, Department of Medicine, Northwell \\ Health, Manhasset, New York, United States \\ ${ }^{2}$ Donald and Barbara Zucker School of Medicine at Hofstra/Northwell, \\ Northwell Health, Manhasset, New York, United States \\ ${ }^{3}$ Division of Health Services Research, Center for Health Innovations \\ and Outcomes Research, Department of Medicine, Northwell \\ Health, Manhasset, New York, United States \\ ${ }^{4}$ Department of Medicine, Anticoagulation and Clinical Thrombosis \\ Services, Northwell Health System, Lenox Hill Hospital, New York, \\ New York, United States
}

TH Open 2018;2:e242-e249.

\section{Andrzej Kozikowski ${ }^{2,3}$ Vidhi Patel ${ }^{3}$ Guang Qiu ${ }^{1}$}

Address for correspondence Jessica Cohen, MD, Northwell Health, 300 Community Drive, Manhasset, NY 11030, United States (e-mail: jcohen11@northwell.edu).

\begin{abstract}
Keywords

- adverse drug events

- anticoagulants

- inpatients

- INR

- warfarin

Background Warfarin's adverse drug events are dangerous, common, and costly. While outpatient warfarin management tools exist, there is a dearth of guidance for inpatients.

Objectives We sought to describe a health system's chronic warfarin quality metrics in older inpatients, defined by international normalized ratio (INR) control, explore associations between INR overshoots and clinical outcomes, and identify factors associated with overshoots.

Patients/Methods Data on patients 65 years and older who were prescribed chronic warfarin and admitted during January 1, 2014, to June 30, 2016, were extracted through retrospective chart review. We defined overshoots as INRs 5 or greater after 48 hours of hospitalization. Logistic regression modeling was used to determine risks for overshoots and multivariate analysis for overshoots' association with length of stay (LOS), bleeding, and mortality.

Results Of the 12,107 older inpatients on chronic warfarin, most were 75 years or older $(75.7 \%)$, female $(51.2 \%)$, and white $(70.0 \%)$. While $1,333(11.0 \%)$ of patients had overshoots during the admission, 449 (33.7\%) of these reached overshoots after 48 hours. When stratified by overshoots versus no overshoots, LOS more than doubled (15.6 vs. 6.8 days) and the bleed rate was significantly higher $(27.4$ vs. $8.3 \%$ ) in the overshoot group. While overall mortality was small (0.4\%), the overshoot group's mortality was significantly higher (3.12 vs. $0.28 \%$ ). Black race and weight were protective against overshoots; history of heart failure and antibiotic/amiodarone exposure were predictive of overshoots.

Conclusion This is the largest study examining warfarin quality metrics for hospitalized adults, specifically older inpatients. Our model may serve as the basis for identifying high-risk warfarin patients to target interventions to reduce adverse drug events.
\end{abstract}

received

March 22, 2018

accepted after revision

June 5, 2018
DOI https://doi.org/

10.1055/s-0038-1667138. ISSN 2512-9465. (c) 2018 Georg Thieme Verlag KG Stuttgart · New York
License terms

()(1) 


\section{Introduction}

The Agency for Healthcare Research and Quality (AHRQ) labels anticoagulants such as warfarin a high-risk drug. Prior studies have shown that the majority of warfarin-associated bleeds result in serious outcomes, with fatal outcomes reported in up to $10 \%{ }^{1}$ Warfarin in particular accounts for the largest number of serious adverse event reports in the Food and Drug Administration's (FDA's) Adverse Event Reporting System for the 1990 and 2000 decades, especially in older patients. ${ }^{1}$ In a Medicare-specific population, $8.8 \%$ of adverse drug events during hospitalizations were attributed to warfarin. ${ }^{2}$ In teaching hospitals, one-third of preventable adverse drug events were related to warfarin. ${ }^{3}$ These warfarin-associated adverse drug events have a significant economic burden as well; a review of medical and pharmacy claims for patients with atrial fibrillation on warfarin found that annual all-cause health care costs in patients with intracranial or gastrointestinal bleeds amount to $\$ 41,903$ per patient and $\$ 40,586$ per patient, respectively, compared with $\$ 24,129$ per patient on warfarin without bleeding. ${ }^{4}$ Given that warfarin-associated adverse drug events are dangerous, common, and costly, the Department of Health and Human Services' National Action Plan for Adverse Drug Event Prevention has identified the safe use of anticoagulation as a national priority. ${ }^{5}$ The Joint Commission's 2017 Hospital National Patient Safety Goals specifically recommend in Aim NPSG.03.05.01 to "Take extra care with patients

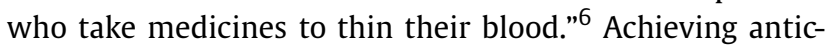
oagulant safety involves minimizing avoidable adverse drug events, reducing variability in provider care, improving system efficiency, and supporting documentation. ${ }^{7}$

Multiple tools exist for warfarin management in the outpatient setting, ${ }^{8-11}$ and dosing algorithms improve time in therapeutic range. ${ }^{12}$ Such outpatient protocols include patient factors that may affect sensitivity to warfarin initiation, and subsequently dose adjusting by weekly percentages. ${ }^{13,14}$ They are not practical for inpatient use, as they do not account for the nuances of inpatient care, such as frequent use of antibiotics or declining kidney function, and the need to adjust doses on a more frequent basis than every week. Unfortunately, there is a dearth of guidance with regard to inpatient warfarin management. ${ }^{15}$ There are very few studies that have explored warfarin management for hospitalized patients; the focus of these studies was on warfarin initiation ${ }^{16}$ or these studies did not account for clinical factors affecting maintenance dose. ${ }^{15}$ Many studies have supported pharmacy-driven inpatient warfarin management as a method for reducing warfarin-associated adverse drug events. ${ }^{15,17,18}$ While this may be effective, it can be impractical, depending on the setting and available resources for dedicating pharmacists to inpatient warfarin management.

We now seek to bridge this gap in warfarin management specifically in the inpatient setting. This study aims to (1) describe a large health system's warfarin quality metrics in older inpatients, defined by the international normalized ratio (INR) control, (2) explore the association between inpatient INR overshoots and clinical outcomes, and (3) identify intrinsic and extrinsic patient factors associated with INR overshoots. We hypothesize that poor warfarin control is common in the inpatient setting and is associated with poor clinical outcomes.

\section{Methods}

We conducted a retrospective chart review at a large health system operating in the New York metropolitan area, encompassing seven hospitals (three tertiary and four community hospitals). Data were extracted from electronic health records of patients 65 years and older who were admitted and treated with chronic warfarin between January 1, 2014, and June 30, 2016. For this study, we defined chronic warfarin as documentation of warfarin use as a home medication prior to admission (i.e., admission medication reconciliation). Our local institutional review board approved the study (IRB \#16-642).

We defined INR overshoots as supratherapeutic INRs of greater than or equal to 5 ; it has previously been shown that the incidence of adverse events, specifically bleeding events, rises steeply with these INR values. ${ }^{19}$ To identify the quality of inpatient warfarin as a result of dosing during the acute hospitalization (rather than doses taken prior to admission), we limited our analysis to INRs after the initial 48 hours of the hospital stay. By hospital policy, warfarin dosing required checking daily INRs. To confirm that this policy was followed, we calculated the percentage of INR days as the number of days with INR values available per length of stay (LOS) for the groups with and without INR overshoots.

Data points collected included all inpatient INR values, patient-related variables (age, height, weight, sex, race, marital status, smoking history), and presence of comorbid conditions (myocardial infarction [MI], congestive heart failure [CHF], peripheral vascular disease [PVD], cerebrovascular disease [CVD], dementia, chronic obstructive pulmonary disease [COPD], connective tissue disease, peptic ulcer disease [PUD], diabetes mellitus (DM), moderate or severe chronic kidney disease [CKD], hemiplegia/paraplegia, malignancies, HIV, and liver disease). Additional variables included medications administered during hospitalization (i.e., antibiotics, amiodarone, and statins) and organizational factors (i.e., tertiary vs. community hospital).

Outcomes included hospital LOS, mortality, and clinically significant bleeding. To capture clinically relevant bleeding, patients needed to meet at least two of the following three criteria: (1) an ICD9 code for bleeding (as a hospital diagnosis), (2) RBCs transfused during admission, and/or (3) receipt of a reversal agent during the admission (including any vitamin $\mathrm{K}$, fresh frozen plasma, or prothrombin complex concentrates). The ICD9 bleeding codes used for analysis were derived from members of the New York State Anticoagulation Coalition and from Leonard et al (2008) and are listed in - Appendix . $^{20}-$ Appendix $B$ clarifies the number of patients who met two or three criteria for bleeding.

Logistic regression modeling was used to determine the risk factors for INR overshoots. Additional multivariate 
analysis was employed to associate INR overshoots with LOS, bleeding, and mortality. Variability across the health system was evaluated with INR overshoots by type of hospital, tertiary care versus community facility. Additional analysis of the impact of patient weight $(\mathrm{kg})$ on INR overshoots was done through chi square testing at $10-\mathrm{kg}$ intervals to establish safety thresholds.

\section{Results}

There were 17,494 unique admissions across seven acute care facilities for patients 65 years and over on warfarin. Of these, 12,107 were on chronic warfarin with INR data available and 5,387 were initiated on warfarin during the hospitalization (not included in our target population). Of those on chronic warfarin, 1,020 (8.4\%) discontinued warfarin on discharge from the hospital. Patients with INR overshoots were more likely to be discharged without warfarin than those without overshoots ( 24.3 vs. $7.8 \%, p<0.0001$ ). - Table 1 describes the characteristics of patients on chronic warfarin during their acute hospitalization. The majority of patients $(75.7 \%)$ were older than 75 years, female (51.2\%), and white (70\%). One-third had a history of smoking, with the most common comorbid conditions being CHF (46\%), DM without chronic complications (31.4\%), CVD (24\%), COPD (22.9\%), moderate/severe CKD (22.2\%), and malignancy (22.1\%).

The percentage of INR days was $96 \%$ of the total LOS for both the groups with and without INR overshoots. - Table 2 presents supratherapeutic INR rates. Of the 12,107 patients, $5,829(48.1 \%)$ became supratherapeutic with an INR greater than 3 during the admission, and $54.2 \%$ of these episodes occurred after the initial 48 hours of hospitalization. While $1,333(11.0 \%)$ of chronic warfarin patients reached an INR greater than or equal to 5 at some point during the admission, 449 (33.7\%) of these reached this maximum INR after the initial 48 hours of the hospital stay. Patients with INR overshoots remained over an INR of 5.0 for a mean of 1.9 days (SD: 1.2 , range: $1-11$ days).

- Table 3 presents outcomes stratified by INR category after the initial 48 hours. When stratified by category (INR overshoots: INR $\geq 5$ after initial 48 hours vs. no INR overshoots: INR $<5$ after initial 48 hours), LOS more than doubled in the group with INR overshoots (6.8 vs. 15.6 days, $<0.0001)$. Overall, the clinically significant bleed rate by our definition was $9 \%$. The group with INR overshoots had a significantly higher bleed rate, compared with the group without INR overshoots ( 27.4 vs. $8.3 \%$, adjusted odds ratio [OR]: $6.2, p<0.0001)$. While the overall mortality rate for the chronic warfarin group was small $(0.4 \%)$, there was a significantly higher mortality rate ( 3.12 vs. $0.28 \%$, adjusted OR: $8.6, p<0.0001$ ) in the group with INR overshoots. There was no significant difference in either the 30 - or 90-day readmission rates between groups.

In evaluating variability in the quality of warfarin management across the seven facilities, the rates of INRs over 5 after the first 48 hours ranged from 3.0 to $5.9 \%$. While there was no significant difference between hospital types (community vs, tertiary) with regard to INR overshoots, admission to a tertiary hospital was found to be protective against bleeding (OR: 0.862, $p<0.0016$ ).

- Table 4 presents demographic, clinical, and organizational variables used in the prediction model for INR overshoots after the initial 48 hours of hospitalization. Using logistic regression, black race and weight were found to be protective against INR overshoots; conversely, history of CHF and antibiotic or amiodarone exposure was predictive of INR overshoots. Moderate or severe CKD trended toward predicting INR overshoots, but did not reach statistical significance $(p<0.068)$. When adding the variable for INR overshoots to the logistic regression model, we found that (in addition to controlling for age, gender, race, smoking status, ICU stay, heart failure, COPD, DM, CKD, malignancy, liver disease, weight, and antibiotic and amiodarone exposure) an INR greater than or equal to 5 was independently predictive of a longer LOS $(p<0.0001)$, higher bleed rate $(p<0.0001)$, and higher mortality $(p<0.0001)$.

Chi-square testing at $10-\mathrm{kg}$ intervals for body weight found significant thresholds at both 50 and $90 \mathrm{~kg}$ : 7.7\% of patients less than or equal to $50 \mathrm{~kg}$ experienced INR overshoots compared with $3.5 \%$ of those over $50 \mathrm{~kg}(p<0.0001)$; $4.1 \%$ of patients less than or equal to $90 \mathrm{~kg}$ experienced INR overshoots compared with $2.5 \%$ of patients over $90 \mathrm{~kg}$ $(p<0.0001)$. At weights over $120 \mathrm{~kg}$, there is no significant difference in incidence of INR overshoots between weight classes. - Table 5 illustrates an overall downward trend of INR overshoots as weight classes increase, with $7.69 \%$ of those $50 \mathrm{~kg}$ and under experiencing overshoots, 3.78\% of those between 50 and $90 \mathrm{~kg}, 2.35 \%$ between 90 and $120 \mathrm{~kg}$, and $2.98 \%$ of those over $120 \mathrm{~kg}$.

\section{Discussion}

This is the largest study to date examining warfarin quality metrics for older adults in the inpatient setting. More specifically, we sought to describe chronic warfarin quality metrics across multiple inpatient facilities, explore the association between inpatient INR overshoots and clinical outcomes, and identify intrinsic patient-related factors and extrinsic factors associated with INR overshoots. Warfarin has previously been described as a high-risk medication, and poor control defined by INR has been associated with negative outcomes; our research is novel in that it specifically investigates the clinical outcomes of INR overshoots in a large hospital-based health system and focuses on risk factors for such overshoots.

Approximately half of the patients on chronic warfarin reached supratherapeutic levels of INR greater than 3 during the admission, and approximately one-half of these occurred after the initial 48 hours of hospitalization. This time frame was used to focus on effects of inpatient, rather than outpatient, events including provider dosing and clinical conditions. Roughly $11 \%$ of patients reached supratherapeutic INRs at the clinically important threshold of INR $\geq 5.0$, and one-third of these reached this level after the initial 48 hours, with inpatient dosing again likely responsible for these INR overshoots. While the overall bleed rate of $9 \%$ is comparable 
Table 1 Patient characteristics: 12,107 chronic warfarin inpatients

\begin{tabular}{|c|c|c|c|}
\hline Characteristics & $\begin{array}{l}\text { Total } \\
N(\%)\end{array}$ & $\begin{array}{l}\text { No overshoots } \\
n(\%)\end{array}$ & $\begin{array}{l}\text { Overshoots } \\
n(\%)\end{array}$ \\
\hline Age $\geq 75$ & $9,172(75.7)$ & $8,834(75.8)$ & $338(75.3)$ \\
\hline Female & $6,203(51.2)$ & $5,943(51.0)$ & 260 (57.9) \\
\hline \multicolumn{4}{|l|}{ Race } \\
\hline White & $8,472(70.0)$ & $8,423(72.2)$ & $322(71.7)$ \\
\hline Black & $1,593(13.1)$ & $1,570(13.5)$ & $44(9.8)$ \\
\hline Other & $880(7.3)$ & $1,219(10.5)$ & $61(13.6)$ \\
\hline Hispanic & $704(5.8)$ & $676(5.8)$ & $28(6.2)$ \\
\hline Asian & $461(3.8)$ & 449 (3.9) & $22(4.9)$ \\
\hline \multicolumn{4}{|l|}{ Marital status } \\
\hline Married & $5,496(45.4)$ & $5,296(45.4)$ & $200(44.5)$ \\
\hline Widowed & $4,144(34.2)$ & $3,993(34.4)$ & 151 (33.6) \\
\hline Single & $1,382(11.4)$ & $1,333(11.4)$ & 49 (10.9) \\
\hline Divorced & $614(5.1)$ & $588(5.0)$ & $26(5.8)$ \\
\hline Other & 409 (3.4) & $390(3.3)$ & $19(4.2)$ \\
\hline Separated & $65(0.5)$ & $61(0.5)$ & $4(0.9)$ \\
\hline Smoker (present/former) & $4,035(33.3)$ & $3,901(33.5)$ & $134(29.8)$ \\
\hline \multicolumn{4}{|l|}{ Comorbid conditions } \\
\hline $\mathrm{CHF}$ & $5,569(46.0)$ & $5,377(46.1)$ & $192(42.8)$ \\
\hline DM without chronic complication & $3801(31.4)$ & $3,668(31.5)$ & $133(29.6)$ \\
\hline CVD & $2,906(24.0)$ & $2,786(23.9)$ & $120(26.7)$ \\
\hline COPD & $2,774(22.9)$ & $2,658(22.8)$ & $116(25.8)$ \\
\hline Moderate/Severe CKD & $2,684(22.2)$ & $2,571(22.1)$ & $113(25.2)$ \\
\hline Malignancy & $2,675(22.1)$ & $2,576(22.1)$ & $99(22.1)$ \\
\hline $\mathrm{MI}$ & $1,656(13.7)$ & $1,594(13.7)$ & $62(13.8)$ \\
\hline PVD & $1,609(13.3)$ & $1,542(13.2)$ & $67(14.9)$ \\
\hline DM with chronic complication & $677(5.6)$ & $647(5.6)$ & $30(6.7)$ \\
\hline Connective tissue disease & $575(4.8)$ & $551(4.7)$ & $24(5.4)$ \\
\hline PUD & $458(3.8)$ & $441(3.8)$ & $17(3.8)$ \\
\hline Liver disease (moderate/severe) & $369(3.1)$ & $356(3.1)$ & $13(2.9)$ \\
\hline Hemiplegia/Paraplegia & $260(2.2)$ & $245(2.1)$ & $15(3.3)$ \\
\hline Metastatic solid tumor & $255(2.1)$ & $245(2.1)$ & $10(2.2)$ \\
\hline Dementia & $135(1.1)$ & $132(1.1)$ & $3(0.7)$ \\
\hline HIV & $9(0.1)$ & $9(0.1)$ & $0(0)$ \\
\hline \multicolumn{4}{|l|}{ Medications } \\
\hline Statins & $7,514(62.1)$ & $7,256(62.2)$ & $258(57.5)$ \\
\hline Antiplatelets & $5,091(42.0)$ & $4,910(42.1)$ & $181(40.3)$ \\
\hline Antibiotics & $1941(16.0)$ & $1,837(15.8)$ & $104(23.2)$ \\
\hline Amiodarone & $968(8.0)$ & 919 (7.9) & 49 (10.9) \\
\hline ICU admission & $1,974(16.3)$ & $1,841(15.8)$ & $133(29.6)$ \\
\hline First INR & $2.6 \pm 1.6$ & $2.6 \pm 1.6$ & $3.6 \pm 2.6$ \\
\hline
\end{tabular}

Abbreviations: CHF, chronic heart failure; CKD, chronic kidney disease; COPD, chronic obstructive pulmonary disease; CVD, cerebrovascular disease; DM, diabetes mellitus; ICU, intensive care unit; INR, international normalized ratio; MI, myocardial infraction; PUD, peptic ulcer disease; PVD, peripheral vascular disease. 
Table 2 Supratherapeutic INRs

\begin{tabular}{|l|l|l|}
\hline INR values & No. of patients & $\%$ \\
\hline INR $>3$ & $5,829 / 12,107$ & 48.1 \\
\hline INR $>3$ after 48 h & $3,157 / 9,873$ & 32.0 \\
\hline INR $\geq 5$ & $1,333 / 12,107$ & 11.0 \\
\hline INR $\geq 5$ after $48 \mathrm{~h}$ & $449 / 9,873$ & 4.6 \\
\hline
\end{tabular}

Abbreviation: INR, international normalized ratio.

to rates reported in Medicare patients on anticoagulation, ${ }^{21}$ the group with INR overshoots had significantly increased LOS, bleeding, and mortality. Given INR overshoots' association with these adverse events, they may serve as potential surrogate markers for identifying such negative outcomes that health systems seek to avoid. By hospital policy, INRs are checked daily for patients presently treated with warfarin. Despite close monitoring with the rate of INR days being $96 \%$ in both the overshoot and no overshoot group, there was still poor control in the overshoot group suggesting that frequency of INR checking did not contribute to differences between adverse outcomes between the groups. Future studies should evaluate interventions to improve the safety of inpatient warfarin dosing and may use INR overshoots in addition to clinical outcomes to evaluate the effectiveness of such interventions.

We found that for older patients on chronic warfarin therapy during acute hospitalization, low weight, exposure to antibiotics/amiodarone, and heart failure were independently predictive of INR overshoots, while black race was protective. In additional weight analysis, the largest thresholds for correlation with INR overshoots were found at 50 and $90 \mathrm{~kg}$. At weights above $120 \mathrm{~kg}$, there were no longer associations with INR overshoots. While most of these factors have been identified as markers, or sensitivity classes for outpatient initiation algorithms, this is the first study to evaluate them in an older inpatient population. As examples, the initiation algorithms presented by the University of North Carolina ${ }^{9}$ and the University of Wisconsin ${ }^{10}$ both include heart failure, low body weight, antibiotics, and amiodarone as intrinsic and extrinsic factors making patients prone to higher warfarin sensitivity. In Kimmel's

Table 3 Outcomes stratified by INR overshoots

\begin{tabular}{|c|l|l|l|l|}
\hline & Overshoots & $\begin{array}{l}\text { No } \\
\text { overshoots }\end{array}$ & $\begin{array}{l}\text { Adjusted } \\
\text { OR }\end{array}$ & $p$-Value \\
\hline $\begin{array}{l}\text { Length of } \\
\text { stay (d) }\end{array}$ & 15.60 & 6.81 & n/a & $<0.0001$ \\
\hline Mortality & $3.12 \%$ & $0.28 \%$ & 8.6 & $<0.0001$ \\
\hline Readmissions & \multicolumn{5}{|l}{} \\
\hline $30 \mathrm{~d}$ & $18.35 \%$ & $20.71 \%$ & $\mathrm{n} / \mathrm{a}$ & 0.1856 \\
\hline $90 \mathrm{~d}$ & $33.28 \%$ & $31.63 \%$ & $\mathrm{n} / \mathrm{a}$ & 0.4647 \\
\hline Bleeding & $27.39 \%$ & $8.27 \%$ & 6.2 & $<0.0001$ \\
\hline
\end{tabular}

Abbreviation: INR, international normalized ratio.
Table 4 Prediction model for INR overshoots: analysis of maximum likelihood estimates

\begin{tabular}{|c|c|c|}
\hline Parameter & Estimate & $p$-Value \\
\hline Intercept & -1.00 & 0.35 \\
\hline Tertiary hospital & -0.01 & 0.93 \\
\hline Age: years & -0.01 & 0.14 \\
\hline Gender: male & -0.22 & 0.10 \\
\hline \multicolumn{3}{|l|}{ Race } \\
\hline Asian & -0.16 & 0.55 \\
\hline White & -0.27 & 0.11 \\
\hline Black & -0.59 & 0.01 \\
\hline Ethnicity: Hispanic & -0.38 & 0.12 \\
\hline \multicolumn{3}{|l|}{ Marital status } \\
\hline Widowed & -0.27 & 0.32 \\
\hline Divorced & -0.03 & 0.92 \\
\hline Married & -0.12 & 0.64 \\
\hline Separated & 0.17 & 0.79 \\
\hline Single & -0.17 & 0.56 \\
\hline Smoker & -0.10 & 0.37 \\
\hline \multicolumn{3}{|l|}{ Comorbid conditions } \\
\hline $\mathrm{MI}$ & -0.03 & 0.82 \\
\hline $\mathrm{CHF}$ & -0.22 & 0.04 \\
\hline PVD & 0.10 & 0.52 \\
\hline CVD & 0.14 & 0.23 \\
\hline Dementia & -1.00 & 0.16 \\
\hline COPD & 0.19 & 0.11 \\
\hline Connective tissue disease & 0.02 & 0.94 \\
\hline PUD & -0.09 & 0.74 \\
\hline $\begin{array}{l}\text { DM without chronic } \\
\text { complication }\end{array}$ & -0.04 & 0.72 \\
\hline $\begin{array}{l}\text { DM with chronic } \\
\text { complication }\end{array}$ & 0.16 & 0.46 \\
\hline Moderate/Severe CKD & 0.23 & 0.07 \\
\hline Hemiplegia/Paraplegia & 0.39 & 0.19 \\
\hline Malignancy & -0.03 & 0.79 \\
\hline Metastatic solid tumor & 0.03 & 0.93 \\
\hline $\begin{array}{l}\text { Moderate/Severe liver } \\
\text { disease }\end{array}$ & -0.17 & 0.57 \\
\hline Height & 0.00 & 0.91 \\
\hline Weight & -0.01 & $<0.01$ \\
\hline \multicolumn{3}{|l|}{ Medications } \\
\hline Statins & -0.19 & 0.07 \\
\hline Antibiotics & 0.43 & 0.00 \\
\hline Amiodarone & 0.38 & 0.02 \\
\hline
\end{tabular}

Abbreviations: $\mathrm{CHF}$, chronic heart failure; CKD, chronic kidney disease; COPD, chronic obstructive pulmonary disease; CVD, cerebrovascular disease; DM, diabetes mellitus; ICU, intensive care unit; INR, international normalized ratio; MI, myocardial infraction; PUD, peptic ulcer disease; PVD, peripheral vascular disease. 
Table 5 INR overshoots by weight classes

\begin{tabular}{|l|l|l|l|}
\hline $\begin{array}{l}\text { Weight } \\
(\mathbf{k g})\end{array}$ & $\begin{array}{l}\text { No overshoots } \\
\boldsymbol{n}(\%)\end{array}$ & $\begin{array}{l}\text { Overshoots } \\
\boldsymbol{n}(\%)\end{array}$ & Chi-square \\
\hline$\leq 50$ & $708(92.31)$ & $59(7.69)$ & $<0.001$ \\
\hline $50.01-90$ & $8,116(96.22)$ & $319(3.78)$ & $<0.001$ \\
\hline $90.01-120$ & $2,283(97.65)$ & $55(2.35)$ & $<0.001$ \\
\hline$>120$ & $489(97.02)$ & $15(2.98)$ & $<0.001$ \\
\hline
\end{tabular}

Abbreviation: INR, international normalized ratio.

pharmacogenetics studies, the clinical dose-revision algorithm that was used as a comparison to pharmacogenetics dosing, black race and body surface area were included as factors increasing the recommended warfarin dose, and amiodarone use as a factor lowering the dose. ${ }^{22}$

There were several limitations to our study. This was a retrospective chart review, and predictors of INR overshoots were limited by documentation available from the electronic health record with incomplete information, and difficulty establishing cause and effect. Comorbid conditions were identified through an electronic data pull of ICD9 codes alone, and thus we were unable to differentiate between acute, chronic, and past conditions or to establish temporal associations between such comorbid conditions and INR overshoots. Bleeding events during hospitalization could not be time correlated with INR overshoots, again highlighting the lack of ability to establish cause and effect. We do hope to have improved accuracy of bleeding events by requiring a minimum of two bleed-related orders or coding but were unable to verify this through individual chart analysis. Furthermore, this definition of bleeding may have impacted the finding that admission to a tertiary hospital was associated with a lower risk of bleeding due to differences in transfusion management such as evidence-based, higher thresholds for transfusions. Additionally, while ICU admission was more prevalent in the INR overshoot group, we were unable to assess whether such admissions were due to a concurrent illness causing the overshoot, severe bleeding caused by the overshoot, or poor dosing within the ICU. We also did not assess for scenarios when warfarin was intentionally held (i.e., for procedures) or the need for reversal due to bleeding. To overcome this barrier, our focus for poor control was on supratherapeutic INRs known to be high risk for acute bleeding episodes rather than on subtherapeutic INRs. On the inpatient setting, the risk of subtherapeutic INRs can be mitigated by using heparin-bridging therapies when appropriate. We did not separate surgical and medical patients who may have different risk factors for adverse events. A final limitation was that the use of antibiotics or amiodarone was not correlated in its timing with the administration of warfarin.

\section{Summary and Conclusion}

Our study findings indicated that (1) INR overshoots are prevalent in the inpatient setting in an older population across our health system and associated with poor outcomes and (2) INR overshoots are independently associated with low weight, heart failure, non-black race, and antibiotic or amiodarone exposure. In the outpatient setting, both intrinsic patientrelated and extrinsic factors are integrated into warfarin dosing algorithms. We found that similar factors are also associated with inpatient INR metrics. Yet, no such tool exists in the inpatient setting to determine appropriate warfarin dosing, especially for more frequent (than weekly) assessments. Our model may serve as the basis for identifying high-risk patients and developing interventions for inpatient warfarin dosing strategies. Future studies should focus on the impact of the rate of change of the INR (the delta INR) on predicting INR overshoots when combined with clinical factors identified by our prediction model. ${ }^{17}$

\section{Conflict of Interest}

None declared.

\section{Acknowledgments}

The authors would like to acknowledge the Center for Health Innovations and Outcomes Research at Northwell Health for their support.

\section{References}

1 Wysowski DK, Nourjah P, Swartz L. Bleeding complications with warfarin use: a prevalent adverse effect resulting in regulatory action. Arch Intern Med 2007;167(13):1414-1419

2 Classen DC, Jaser L, Budnitz DS. Adverse drug events among hospitalized Medicare patients: epidemiology and national estimates from a new approach to surveillance. Jt Comm J Qual Patient Saf 2010;36(01):12-21

3 Winterstein AG, Hatton RC, Gonzalez-Rothi R, Johns TE, Segal R. Identifying clinically significant preventable adverse drug events through a hospital's database of adverse drug reaction reports. Am J Health Syst Pharm 2002;59(18):1742-1749

4 Ghate SR, Biskupiak J, Ye X, Kwong WJ, Brixner DI. All-cause and bleeding-related health care costs in warfarin-treated patients with atrial fibrillation. J Manag Care Pharm 2011;17(09):672-684

5 Harris Y, Hu DJ, Lee C, Mistry M, York A, Johnson TK. Advancing medication safety: establishing a national action plan for adverse drug event prevention. Jt Comm J Qual Patient Saf 2015;41(08):351-360

6 The Joint Commission. National Patient Safety Goals. 03.05.01. Available at: https://www.jointcommission.org/assets/1/6/2017_ NPSG_HAP_ER.pdf. Accessed August 28, 2017

7 Spyropoulos AC, Viscusi A, Singhal N, et al. Features of electronic health records necessary for the delivery of optimized anticoagulant therapy: consensus of the EHR Task Force of the New York State Anticoagulation Coalition. Ann Pharmacother 2015;49 (01):113-124

8 Garcia DA, Schwartz MJ. Warfarin therapy: tips and tools for better control. J Fam Pract 2011;60(02):70-75

9 Initiation Warfarin Dosing Protocol. University of North Carolina GIM Anticoagulation Clinic Algorithm; 2001-UNC Center of Excellence in Chronic Illness. [cited 2017 Oct 20]. Available at: https:// www.med.unc.edu/im/files/enhanced-care-files/anticoag-files/ Initiation\%20Warfarin\%20Dosing\%20Protocol.pdf. Accessed June 27, 2018

10 Inpatient Warfarin Guideline [Internet]. University of Wisconsin UW Health. Warfarin Management - Adult - Inpatient Clinical Practice Guide. [cited 2017 Oct 20]. Available at: https://www. uwhealth.org/files/uwhealth/docs/pdf3/Inpatient_Warfarin_ Guideline.pdf. Accessed June 27, 2018 
11 Hamilton General Warfarin Dosing Nomogram [Internet]. [cited 2017 Oct 20]. Available at: https://static-content.springer.com/ esm/art\%3A10.1007\%2Fs11239-013-0969-x/MediaObjects/ 11239_2013_969_MOESM1_ESM.pdf. Accessed June 27, 2018

12 Van Spall HG, Wallentin L, Yusuf S, et al. Variation in warfarin dose adjustment practice is responsible for differences in the quality of anticoagulation control between centers and countries: an analysis of patients receiving warfarin in the randomized evaluation of long-term anticoagulation therapy (RE-LY) trial. Circulation 2012;126(19):2309-2316

13 Warfarin Management - Adult - Ambulatory Clinical Practice Guideline [Internet]. UW Health; [cited 2017 Aug 28]. Available at: http://www.uwhealth.org/files/uwhealth/docs/pdf2/Ambulatory_Warfarin_Guideline.pdf. Accessed June 27, 2018

14 UNMH Anticoagulation Subcommittee. Warfarin Dosing Guideline [Internet]. UNM Hospitals; 2013 [cited 2017 Aug 28]. Available at: http://excellence.acforum.org/sites/default/files/warfarin \%20dosing\%20guideline\%204_5_AB.pdf. Accessed June 27, 2018

15 Dawson NL, Porter IE II, Klipa D, et al. Inpatient warfarin management: pharmacist management using a detailed dosing protocol. J Thromb Thrombolysis 2012;33(02):178-184

16 Gouin-Thibault I, Levy C, Pautas E, et al. Improving anticoagulation control in hospitalized elderly patients on warfarin. J Am Geriatr Soc 2010;58(02):242-247

\section{Appendix A ICD9 codes bleeding}

\begin{tabular}{|l|l|}
\hline ICD 9 Code & Definition \\
\hline 2463 & Hemorrhage and infarction of thyroid \\
\hline 2554 & Corticoadrenal insufficiency \\
\hline 2851 & Acute posthemorrhagic anemia \\
\hline 2865 & $\begin{array}{l}\text { Hemorrhagic disorder due to circulating } \\
\text { anticoagulants }\end{array}$ \\
\hline 2867 & Acquired coagulation factor deficiency \\
\hline 2869 & Other and unspecified coagulation defect \\
\hline 3361 & Vascular myelopathies \\
\hline 36281 & Retinal hemorrhage \\
\hline 3636 & Choroidal hemorrhage and rupture \\
\hline 36441 & Hyphema of iris and ciliary body \\
\hline 3688 & Other specified visual disturbances \\
\hline 37272 & Conjunctival hemorrhage \\
\hline 37481 & Hemorrhage of eyelid \\
\hline 37632 & Orbital hemorrhage \\
\hline 37742 & Hemorrhage in optic nerve sheaths \\
\hline 37923 & Vitreous hemorrhage \\
\hline 38869 & Other otorrhea \\
\hline 4230 & Hemopericardium \\
\hline 430 & Subarachnoid hemorrhage \\
\hline 431 & Intracerebral hemorrhage \\
\hline 432 & Hemor and unspecified intracerebral \\
\hline 436 & Hypotension \\
\hline 458 & Hemorrhage unspecified \\
\hline 4590 & \\
\hline &
\end{tabular}

17 Metersky ML, Eldridge N, Wang Y, et al. Predictors of warfarinassociated adverse events in hospitalized patients: opportunities to prevent patient harm. J Hosp Med 2016;11(04): 276-282

18 Sharma M, Krishnamurthy M, Snyder R, Mauro J. Reducing Error in Anticoagulant Dosing via Multidisciplinary Team Rounding at Point of Care. Clin Pract [Internet]. 2017 Apr 20 [cited 2017 Aug 28];7(2). Available at: http://www.ncbi.nlm.nih.gov/pmc/articles/PMC5406843/. Accessed June 27, 2018

19 Cannegieter SC, Rosendaal FR, Wintzen AR, van der Meer FJ Vandenbroucke JP, Briët E. Optimal oral anticoagulant therapy in patients with mechanical heart valves. N Engl J Med 1995;333 (01):11-17

20 Leonard CE, Haynes K, Localio AR, et al. Diagnostic E-codes for commonly used, narrow therapeutic index medications poorly predict adverse drug events. J Clin Epidemiol 2008;61(06): 561-571

21 Bond CA, Raehl CL. Pharmacist-provided anticoagulation management in United States hospitals: death rates, length of stay, Medicare charges, bleeding complications, and transfusions. Pharmacotherapy 2004;24(08):953-963

22 Kimmel SE, French B, Kasner SE, et al; COAG Investigators. A pharmacogenetic versus a clinical algorithm for warfarin dosing. N Engl J Med 2013;369(24):2283-2293

\section{Appendix A (Continued)}

\begin{tabular}{|l|l|}
\hline ICD 9 Code & Definition \\
\hline 5238 & Other specified periodontal diseases \\
\hline 4560 & Gastrointestinal hemorrhage of some sort \\
\hline 45520 & Gastrointestinal hemorrhage of some sort \\
\hline 45550 & Gastrointestinal hemorrhage of some sort \\
\hline 45580 & Gastrointestinal hemorrhage of some sort \\
\hline 45620 & Gastrointestinal hemorrhage of some sort \\
\hline 53021 & Gastrointestinal hemorrhage of some sort \\
\hline 5310 & Gastrointestinal hemorrhage of some sort \\
\hline 5312 & Gastrointestinal hemorrhage of some sort \\
\hline 5314 & Gastrointestinal hemorrhage of some sort \\
\hline 53140 & Gastrointestinal hemorrhage of some sort \\
\hline 5316 & Gastrointestinal hemorrhage of some sort \\
\hline 532 & Gastrointestinal hemorrhage of some sort \\
\hline 5330 & Gastrointestinal hemorrhage of some sort \\
\hline 5332 & Gastrointestinal hemorrhage of some sort \\
\hline 5334 & Gastrointestinal hemorrhage of some sort \\
\hline 5336 & Gastrointestinal hemorrhage of some sort \\
\hline 5340 & Gastrointestinal hemorrhage of some sort \\
\hline 5342 & Gastrointestinal hemorrhage of some sort \\
\hline 5344 & Gastrointestinal hemorrhage of some sort \\
\hline 5346 & Gastrointestinal hemorrhage of some sort \\
\hline 53511 & Gastrointestinal hemorrhage of some sort \\
\hline 53521 & Gastrointestinal hemorrhage of some sort \\
\hline 53531 &
\end{tabular}


Appendix A (Continued)

\begin{tabular}{|c|c|}
\hline ICD 9 Code & Definition \\
\hline 53551 & Gastrointestinal hemorrhage of some sort \\
\hline 53561 & Gastrointestinal hemorrhage of some sort \\
\hline 56202 & Gastrointestinal hemorrhage of some sort \\
\hline 56203 & Gastrointestinal hemorrhage of some sort \\
\hline 56212 & Gastrointestinal hemorrhage of some sort \\
\hline 56213 & Gastrointestinal hemorrhage of some sort \\
\hline 56881 & Gastrointestinal hemorrhage of some sort \\
\hline 56935 & Gastrointestinal hemorrhage of some sort \\
\hline 5789 & Gastrointestinal hemorrhage of some sort \\
\hline 5780 & Gastrointestinal hemorrhage of some sort \\
\hline 56985 & Gastrointestinal hemorrhage of some sort \\
\hline 5351 & Atrophic gastritis \\
\hline 5368 & $\begin{array}{l}\text { Dyspepsia and other specified disorders of } \\
\text { function of stomach }\end{array}$ \\
\hline 53783 & $\begin{array}{l}\text { Angiodysplasia of stomach and duodenum } \\
\text { with hemorrhage }\end{array}$ \\
\hline 5582 & Toxic gastroenteritis and colitis \\
\hline 5738 & Other specified disorders of liver \\
\hline 5967 & Hemorrhage into bladder wall \\
\hline 5968 & Other specified disorders of bladder \\
\hline 5997 & Hematuria \\
\hline 59989 & $\begin{array}{l}\text { Other specified disorders of the urinary } \\
\text { tract }\end{array}$ \\
\hline 6021 & Congestion or hemorrhage of prostate \\
\hline 6201 & Corpus luteum cyst or hematoma \\
\hline 6228 & $\begin{array}{l}\text { Other specified noninflammatory disor- } \\
\text { ders of cervix }\end{array}$ \\
\hline 6238 & $\begin{array}{l}\text { Other specified noninflammatory disor- } \\
\text { ders of vagina }\end{array}$ \\
\hline 6262 & Excessive or frequent menstruation \\
\hline 6268 & $\begin{array}{l}\text { Other disorders of menstruation and other } \\
\text { abnormal bleeding from female }\end{array}$ \\
\hline 6269 & $\begin{array}{l}\text { Unspecified disorders of menstruation and } \\
\text { other abnormal bleeding from female }\end{array}$ \\
\hline 719 & Hemarthrosis \\
\hline 7802 & Syncope and collapse \\
\hline 7804 & Dizziness and giddiness \\
\hline 7807 & Malaise and fatigue \\
\hline 78079 & Other malaise and fatigue \\
\hline 7827 & Spontaneous ecchymoses \\
\hline 7847 & Epistaxis \\
\hline 7848 & Hemorrhage from throat \\
\hline 7855 & Shock without mention of trauma \\
\hline 7863 & Hemoptysis \\
\hline 7870 & Nausea and vomiting \\
\hline
\end{tabular}

(Continued)
Appendix A (Continued)

\begin{tabular}{|c|c|}
\hline ICD 9 Code & Definition \\
\hline 78799 & $\begin{array}{l}\text { Other symptoms involving digestive } \\
\text { system }\end{array}$ \\
\hline 7890 & Abdominal pain \\
\hline 7899 & $\begin{array}{l}\text { Other symptoms involving abdomen and } \\
\text { pelvis }\end{array}$ \\
\hline 7992 & Nervousness \\
\hline $800-91999$ & Injury from fall or other causes \\
\hline $925-95999$ & Other injuries \\
\hline E8582 & $\begin{array}{l}\text { Accidental poisoning by agents primarily } \\
\text { affecting blood constituents }\end{array}$ \\
\hline E880-E88899 & Accidental falls \\
\hline 920 & $\begin{array}{l}\text { Contusion of face scalp and neck except } \\
\text { eye }\end{array}$ \\
\hline 921 & Contusion of eye and adnexa \\
\hline 922 & Contusion of trunk \\
\hline 923 & Contusion of upper limb \\
\hline 924 & $\begin{array}{l}\text { Contusion of lower limb and other } \\
\text { unspecified sites }\end{array}$ \\
\hline E9342 & Anticoagulants causing adverse effects \\
\hline E9343 & $\begin{array}{l}\text { Vitamin K phytonadione causing adverse } \\
\text { effects in therapeutic use }\end{array}$ \\
\hline E9504 & $\begin{array}{l}\text { Suicide and self-inflicted poisoning by } \\
\text { other specified drugs }\end{array}$ \\
\hline E9620 & Assault by drugs and medicinal substances \\
\hline 9642 & Poisoning by anticoagulants \\
\hline 9643 & Poisoning by vitamin $\mathrm{K}$ \\
\hline 9645 & Poisoning by anticoagulant antagonists \\
\hline E9804 & Poisoning by other specified drugs \\
\hline 9952 & $\begin{array}{l}\text { Unspecified adverse effect of drugs or } \\
\text { medicinal substances }\end{array}$ \\
\hline 9981 & Hemorrhage or hematoma or seroma \\
\hline 5781 & Blood in stool \\
\hline 79092 & Abnormal coagulation profile \\
\hline
\end{tabular}

Notes: These codes were derived from members of the New York State Anticoagulation Coalition and primarily from Leonard et al (2008). ${ }^{20}$

\section{Appendix B}

\begin{tabular}{|l|l|l|l|l|}
\hline $\begin{array}{l}\text { Bleeding } \\
\text { count }\end{array}$ & Frequency & Percent & $\begin{array}{l}\text { Cumulative } \\
\text { frequency }\end{array}$ & $\begin{array}{l}\text { Cumulative } \\
\text { percent }\end{array}$ \\
\hline 0 & 11,646 & 66.57 & 11,646 & 66.57 \\
\hline 1 & 4,225 & 24.15 & 15,871 & 90.72 \\
\hline 2 & 1,423 & 8.13 & 17,294 & 98.86 \\
\hline 3 & 200 & 1.14 & 17,494 & 100.00 \\
\hline
\end{tabular}

